Natalia M. ALEKSEEVA

Postgraduate Student of the English Grammar Department of Odessa National I. I. Mechnikov University, Frantsuzskij blvrd, 24/26, Ukraine, Odessa, (available at:) 65058; tel.: +380974342467; e-mail: natalie.m.alekseeva@gmail.com; ORCID ID: 0000-0001-9304-7251

\title{
STRUCTURAL TYPOLOGY OF HIPPONYMS
}

Summary. The article concentrates on issues of the identification of existing types of hipponymic nomination, which somehow reflects the formation of the English-speaking (naive» profane picture of the world. The main features of the new class of names - the names of horses (hipponyms) - were identified in the previous studies. In this study, an attempt was made to adapt the classification of M. N. Torchinsky for describing hipponyms according to structural features, to cover the various zones of functioning of the investigated onyms and to identify the main structural features of the current hipponymicon. The purpose of the article is to describe various types of hipponyms according to their structural features. The object of the study is the names of horses of different types in the UK and the USA. The subject of the research is structural typology of the hipponyms of these regions. The research material includes register lists of names, analytical sites with official materials dedicated to the equestrian world, ratings and under. As the result of the study, three structural models were singled out - simple (and their subtypes: non-suffix, prefixal, suffixal and confixal), complex (and their subtypes: composites proper, affixal composites, abbreviations or complex abbreviations) and composite (and their subtypes: word combinations, word combinations nominal and phrases) - among the three categories of hipponyms (real, virtual and sacral). It was found that the most frequently used structural model of official hipponyms is composite, whereas informal hipponyms have predominantly simple structure. The sacral hipponyms of Great Britain and the United States were not found and, as a result, were not reflected in our sample. To complete the research, descriptive and structural methods were used extensively. These methods allow describing structure of hipponyms. The results of the research are of value to further development and modernization of onomastics.

Key words: structure, hipponym, hipponymicon, hippostem.

Статтю отримано 21.04.2018 p.

http://dx.doi.org/10.18524/2307-4558.2018.29.139320

УДК 81'[811.161.1+811.163.2]'373.42

\section{БОЕВА Эвелина Владимировна,}

кандидат филологических наук, доцент кафедры украинской и зарубежной литератур Государственного учреждения (Южноукраинский национальный педагогический университет имени К. Д. Ушинского», ул. Старопортофранковская, 26, Одесса, 65020, Украина; тел.: +300487234098; e-mail: evelinaboeva@gmail.com; ORCID ID: 0000-0001-5966-0538

\section{СЕМАНТИЧЕСКАЯ ПОЛЯРИЗАЦИЯ ИМЁН ЛИКВИДИРУЮЩИХ ДЕЙСТВИЙ В РУССКОМ И БОЛГАРСКОМ ЯЗЫКАХ}

Аннотация. Актуальность работы определяется как нарастающим интересом к сопоставительно-типологическому изучению языков, так и попытками обобщить накопившиеся наблюдения над спецификой языкового выражения на разных уровнях, поиском адекватных моделей соотношения языкового и внеязыкового. Предметом нашего исследования служат русские и болгарские глаголы и лексикографические интерпретации их значений. Материалом исследования послужили толковые, синонимические, фразеологические и переводные словари русского и болгарского языков. Основной цельюисследования является установление семиотических оснований имплицитности, типизация этих оснований и создание адекватной модели соотношения языкового и подъязыкового как для одного языка, так и для двух языков, находящихся в отношении близкого родства. Выводы. В группе эпилоговых номинаций наблюдается внутреннее распределение имён в зависимости от концептуальных граней результата. В группе проспективных номинаций единство сохраняется благодаря тезаурусным импликациям значений. В эти импликации входит обязательная ссылка на типическую ситуацию, типические объекты и средства ликвидации.

Ключевые слова: семантическая поляризация, глагол, ликвидирующее действие, субъект, объект, эссенциальные качества.

Постановка проблемы. Современное сопоставительное языкознание имеет своей предпосылкой инвариантность человеческого мышления. Задачей сопоставительной типологии является определение соотношения всеобего, общего и специфического в сравниваемых языках. Значение сопоставительных исследований отмечалось следующими исследователями: В. В. Виноградовым, А. И. Смирницким, В. Н. Ярцевой, А. В. Исаченко, Ш. Балли. Сопоставительное изучение разносистемных языков, наряду с общими особенностями, выявляет расхождения между ними, обогащает языкознание новыми научными фоктами. 
Постановка исследовательских задач. Актуальность представленной работы определяется как нарастающим интересом к сопоставительно-типологическому изучению языков, так и попытками обобщить накопившиеся наблюдения над спецификой языкового выражения на разных уровнях. Предметом исследования служат глаголы ликвидирующих действий в русском и болгарском языках, лексикографические интерпретации их значений. Материалом исследования послужили толковые, синонимические, фразеологические и переводные словари русского и болгарского языков. Основной целью исследования является установление семиотических оснований имплицирования, типизация этих оснований и создание адекватной модели соотношения языкового и подъязыкового как для одного языка, так и для двух языков, находящихся в отношениях близкого родства.

Изложение основного материала.Как известно ликвидирующее действие узнаётся по экзистенциальному результату. Он может быть определён с точки зрения целесообразностидействия как то, чего добивается субъект (например, казнить - наказание, победить - победа, лгать - ложь, обманывать - обман). Второе определение будет экзистенциальным: результат - это то, что остаётся от объекта (болг. руинирал -руини, русск. разваливать - развалины). Результат можно представить в виде динамического процесса (разрушать - рушиться, распадаться). Можно дать и отрицательное определение результата: то, чего объект не может, не в состоянии больше делать (напр.: аннулировать договор - договор не в силе, ломать машину - машина не действует). Наконец, можно дать собственно номинативное определение: результат - это то, к чему нельзя применить прежнего названия, или то, что нужно назвать другим именем (напр.: yбить - mpyn, мёртвое тело).

Результат объективно присущ способу действия, его можно предусмотреть. По нашим наблюдениям, не всегда и не все признаки способа действия являются для говорящего одинаково актуальными. Механизм актуализации этих признаков не является параллельным производству слов, он всегда действует с опережением и остается в резерве номинации. Если бы это было не так, то каждый глагол включал бы в обязательном порядке обозначение способа действия (ср. глаголы мертвить, морить, губить, гноить и др.).

И всё-таки необходимо знать типичные признаки действия, которое, будучи направленным на объект и интенсивным свыше меры, ведёт к его ликвидации. В своей совокупности эти признаки характеризуют простые действия, для выполнения которых не требуется специальных средств: способ воздействия: а) удар, толчок - русск. $\langle$ уарять $>/$ болг. $\langle y \partial а р\rangle$; б) растяжение- русск. $\langle$ растя-

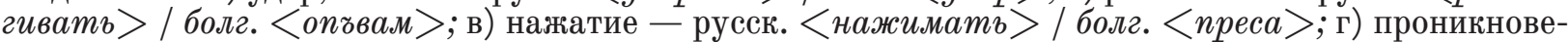

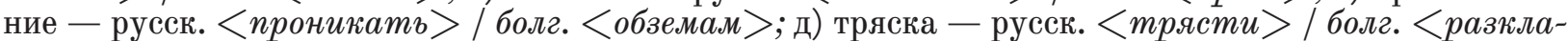
шане >. Нами зафиксированы глаголы: русск. бить, душить, колоть, рвать, вонзить, воткнуть, всадить, тыкать, пороть, рубить, давить, драть, топтать, резать, стрелять, сеиь, стучать, хлопать, пронзать, пронизьвать, разить, колотить, мять, трепать, членить, вешать, лолать и др.; болг. беся, бия, душа, коля, кәсам, муша, бучкам, сека, газя, мачкам, смазвал, стикам, режа, разединявам, нищя, разпгвам, чопля, чепя, разчеквам, рггам, иупя, троша, удавям, удрям, тупам, трепя, шибам [3] и др.

Кроме того, можно указать типические ситуации, в которых прослеживается внутренняя логика конфоликта: война, охота, противоборство, противостояние во всех иных формах, казнь по решению суда, жертвоприношения, удовлетворение потребительских желаний субъекта (в том числе аномальных) и т. д. Нетипичными считаются стихийные бедствия, несчастные случаи, аварии и т. д. Экспансивные ликвидирующие действия образуют ситуации первого типа.

Вторая особенность экспансивных ликвидирующих действий состоит в том, что они направлены на изменение эссенциальных качеств объекта, независимо от точки приложения усилий субъекта (напр.: русск. вешать, давить, резать, расстреливать, убить, улертвить, уничтожить; болг. окачване, смачкване, клане, убиване, унищожаване и т. д.). Семантика ликвидирующего действия связана с их трансформацией в противоположные.

Эссенциальные качества объекта не участвуют в простой лексической номинации: в вербальной семантике действия на них наложен запрет в силу противоположности смысла. Эксплицитное указание на них привело бы к тавтологиям, подобным *яблоку ветки, *носу лица, *вишне дерева. Эссенциальные качества объекта являются таким (семантическим партитивом», который не может присоединяться эксплицитно к имени результата действия. Нет формального запрета на образование глаголов *обезживить, *обезжизнитв(при антонимичном обессмертить - обезсмгртявам), но есть блокирующий механизм подъязыка, где результат соотнесён напрямую с исходным признаком объекта.

Отсюда вытекает особенность ликвидирующих имён, а именно -трансформативный характер значения и его тезаурусная мотивированность. Эпилоговые номинации ликвидирующих действий являются трансформативами эссенциальных признаков объекта. Это понятие можно поставить в основу классификации имён: в соответствии с ним глаголы делятся на проспективные и эпилоговые. Первые, как мы отметили, специализированы в обозначении семантики средства - способа действия (напр.: русск. резать, колоть, рвать, мять; болг. режа, сека, муша, жzсал и др. под.). Семантика результата приписывается им опосредованно в зависимости от того, кто или что является 
объектом действия и в какой ситуации (типической или нет) производится действие. В силу того, что они включают в себя прежде всего признаки элементарных воздействий (напр.: русск. удар, нажатие, растяжение, проникновение; болг. удари, натиснете, протегнете, проникнете и т. д.), которые вообще нейтральны, ликвидирующее значение, как правило, вторично, наслаивается на эти признаки и вместе с ними образует семантику способа-результата. На этом основании глаголы подобного типа относят к каузативам, выражающим каузирующее явление [6, с. 146-147]. Движение от первой группы ко второй охватывает не все проспективные номинации, для этого должна быть совершена дополнительная процедура вторичного означивания, а толкование этих вторичных значений включает в обязательном порядке эпилоговый глагол: резать - убивать острым орудием; колоть - убивать чем-н. острым. Мы пока не касаемся морфологических средств и способов перевода исходного слова в разряд производных эпилоговых номинаций. Дальнейшая дифференциация слов в обеих группах строится с уиётом элементарных признаков способа-средства воздействия и экзистенциальных признаков результата (для эпилоговых номинаций).

Наблюдения над значениями слов в русском и болгарском языках позволяют поставить ещё ряд вопросов: 1) вопрос об объекте ликвидирующего действия; 2) вопрос о роли оценки в номинации действия; 3) вопрос о том, форма какого понятия приспособлена для глагольного обозначения результата действия.

Общее имя объекта ликвидирующего действия - пациенс. Если он живое существо, то его родовым названием будет существительное жертва (учитывается комплекс сострадания, сопровождающий оценку экспансии). Во всех остальных случаях он является предметом, положением дел. Из предметов выделяются артефакты, ценность которых пропорциональна усилиям, приложенным для их изготовления. Остальные предметы обладают ценностью, пропорциональной потребительским желаниям говорящих. Положение вещей в социальной сфере может служить источником неудовлетворенности и желания корректировать те или иные процессы в пользу субъекта. Таким образом, можно выделить сложные действия, ликвидирующие не отдельный предмет, а целое положение вещей, в том числе и в идеальной сфере (напр., глаголы русск. отленить, аннулировать, отиислить, уволить; болг. анулиране, отхвърляне и др.). Такова, в частности, смена властей, сопровождаемая насилием, другие ситуации, в которых объект по некоторым критериям оценивается как “враг, противник, соперник», которого нужно либо победить, либо уничтожить, либо устранить. Уже этих примеров достаточно, чтобы показать многомерность объекта ликвидации, а отсюда — трудности при установлении корпуса имён с ликвидативной семантикой.

Оценка ликвидирующего действия отражает позицию объекта (в данном случае он не совпадает с объектом, а выступает в роли судьи): неприятие любой экспансии, в том числе и той, которая направлена на изменение эссенциальных свойств объекта. Оценка не абсолютна, но служит ориентиром в приближении к идеализированной модели мира, построенной на признании устойчивых норм [см. 2, с. 58-59]. Как известно, оценка ликвидирующего действия базируется на противопоставлении ценности объекта и объективной направленности действия, выражает антагонизм первого и второго. Она квалифицирует действия как (из ряда вон выходящие) и с этой точки зрения является невысказанной претензией.

Оценка, точнее стереотип оценки [см. 4, с. 56-61], лежит в основе образа врага, соперника. В принципе всякое ликвидирующее действие предваряется девальвацией объекта. Таким же образом на основании оценки в корпус имен вводится группа глаголов, обозначающих типические ситуации противоборства, противостояния. Происходит подмена эссенциальных качеств объекта теми качествами, которые создают образ врага. Соответственно, срабатывает стереотип вертикального видения ситуации - целью является не столько уничтожение соперника, сколько желание (положить его на лопатки) и оказаться над ним. Это сказывается на выборе лексем: русск. повергнуть, низложить, низвергнуть, преодолеть; болг. отпаднала, свалят, преодолее, в привлечении (Внештатных) средств номинации типа уложить, косить, сбить и т. д. В болгарском языке фиксируется целая парадигма префиксальных глаголов с ведущим формальным признаком “оказаться выше кого-л.», над кем-л.: надвивам, надмогвал, надделявам, надмятам, надстрелвал и т. д. Все эти факты свидетельствуют о том, что оценка может вносить существенные поправки в формальнологическое определение ликвидации. С последней констатацией связан вопрос о призматичности номинации. Речь идёт о количественном исчислении понятий, которые могли бы стать опорой для глагольного обозначения результата в двух языках. В этих понятиях подведён итог номинации, поэтому их можно определить как концептуальные контуры действия, рассматриваемого в сффере объекта. Другими словами, можно говорить о варьирующем концептуальном отражении результатов экспансии и о том, каков конечный пункт действия в пределах концепта. В результате наших наблюдений мы получили такую картину экзистенциального результата:

1) “Ноль (nulla); ничто; ничего не значащий». Глаголы: русск. аннулировать, уничтожить; болг. анулирам, унищожавам, а также соотносимые с ними дескрипции превратить в «ичто», правя на «нищо»). Объект (предмет, живое существо или ситуация) в признаках данного концепта соотносится с экзистенциальным определением результата: уничтожение - это действие, в результате которого от объекта не остаётся никаких материальных следов. 
2) “Конец». Глаголы: русск. кониить, прикониить, покониить (c), закрыть, прекратить; болг. довършвам, закривам, прекратявам (а также дескрипции положить конеи чему л., слагам край на нещо). Объект соотносится с потребительским определением результата как (то, чего добивается субъект», или: “отнять перспективу развития, продолжения чего-либо».

3) “Исчезновение». Исчезнувшим (либо отсутствующим) является объект, который выпадает из поля зрения и сферы действия говорящего. Глаголы: русск. губить, извести, убрать, исклюиить, снести, болг. погубвам, затривам, изключвам, премахвам, отстранявам. Объект соотносится с потребительским определением результата: совершить какое-то действие в рамках этого концепта значит сделать так, чтобы объекта больше не было видно (соответственно, чтобы не мешал субъекту).

4) “Смерть, небытие». Глаголы: русск. убивать, морить, мертвить, истреблять; болг. убивал, моря, умзртвявам, изтребвам (а также дескрипции делать мёртвым, причинять смерть, (бить) до смерти; правя мзртгв, причинявам смгрт, (бия) до слғрт). Объект соотносится с динамическим определением результата (то, что происходит с объектом - умирать, мертветь). Глаголы этой группы являются трансформативами экзистенциальных признаков (живой», “быть, существовать).

5) “Преимущество силы». Глаголы: русск. победить, одолеть, осилить, пересилить, превозмочь; болг. победя, преодолея, надделея, надмогна, превъзмогна (а также дескрипции добиться победы, одержать победу; печеля победа). Объект номинации соотносится с потребительским определением результата: победить - (добиться преимущества своей силы в противоборстве с кем-чем-л.». Глаголы являются трансформативами стереотипного признака (враг, соперник».

6) “Пустота». Глаголы: русск. опустошать, разорять; болг. опустошавам, разорявам (и перифразы делать пустым, лишённым полноты содержания; правя пуст, карам да опустее). Объекты соотносятся с экзистенциальным определением результата: опустошать - не оставить в объекте ничего ценного, существенного.

7) “Обрыв, срыв, падение». Глаголы: русск. ломать, разваливать, рушить, разрушать, искоренять, исторгнуть, низвергать, валить; болг. иупя, развалям, руша, разрушавам, изкоренявам, провалям, изтрғгвал. Имена действий связаны с вертикальным видением ситуации (исходный признак визуальный: (стоять, держаться)). Объекты соотносятся с динамическим определением результата - (то, что происходит с объектом».

8) “Остатки», “пух и прах». Глаголы: русск. крошить, крушить, громить, испепелять, разлагать [1]; болг. троша, сзкрушавам, разгромявам, изпепелявам, разтурвам, сзсипвал, разпердушинвам [5]. Объекты соотнесены с экзистенциальным определением результата: это действия превращения объекта в мелкие, пространственно удалённые частицы, в бесформенную массу.

Можно предположить, что перечисленные выше способы (видения) результата наиболее существенны для русского и болгарского языков. В основном корпусе мы обнаруживаем гомогенные двоичные знаки, различия же затрагивают не принцип, а средства обозначения. Кроме того, концептуальные грани результата не предъявляют жёстких требований к говорящему. Наоборот, они допускают возможность перехода от одного концепта к другому, что позволяет говорить о полисемичности результата, ср.: [враг] убит, уничтожен, повержен, стёрт с лича земли, побеждён, разгромлен, разбит в пух и прах и т. д. Предпочтение к объекту (убить - к живому, разрушить - к большому, неживому, низвергнуть - к режиму власти, победить - к сопротивляющемуся, снести - к стоящему и т. д.) не препятствует глаголам (набирать очки» в смежных сфоерах результата. Это обнаруживается и в синонимических толкованиях значений, особенно косвенных.

Итак, в группе эпилоговых номинаций наблюдается внутреннее распределение имён в зависимости от концептуальных граней результата. В группе проспективных номинаций единство сохраняется благодаря тезаурусным импликациям значений. В эти импликации входит обязательная ссылка на типическую ситуацию, типические объекты и средства ликвидации. Вне импликаций значения глаголов рубить, давить, колоть, резать (болг. режа, муша, сека, късам) и др. нейтральны.

В особую группу выделяются проспективные номинации, образованные от имени орудия ликвидации: русск. бомбить, бомбардировать, торпедировать, минировать, таранить [1]; болг. бомбардирам, минирам, удрям с таран, торпилирал [5]. Очевидно, толкования типа “сбрасывать

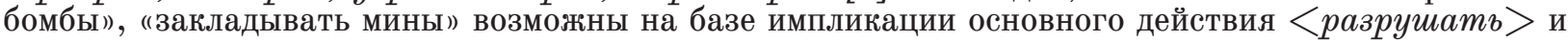
являются денотативной интерпретацией значений.

Выводы. Таким образом, сопоставление имён ликвидирующих действий в двух родственных языках базируется на признании существенности фактора этимологической общности их словарей. Вторым основным положением является понятие вертикальной, тезаурусной мотивации значений слов, в соответствии с которой они выполняют функции обозначения типических действий. 
Литература

1. Александрова З. Е. Словарь синонимов русского языка / ред. Л. А. Чешко. - М. : Русский язык, 1986. 600 c.

2. Арутюнова Н. Д. Оценка. Событие. Факт. - М. : Наука, 1988. - 341 с.

3. Болгарско-русский словарь / сост. С. Б. Бернштейн. - М. : Советская энциклопедия, 1966. - 768 с.

4. Вольф E. M. Функциональная семантика оценки. - М. : Наука, 1985. - 228 с.

5. Димитрова M., Спасова А. Синонимен речник на съвременния български книжовен език. - София : Изд-во на БАН, $1980 .-734 \mathrm{c}$.

6. Динева A. Семантика на каузативните глаголи в български език // Български език. - София, 1985. - № 2. C. $140-148$.

\section{References}

1. Aleksandrova, Z. E. (1986), Dictionary of synonyms of the Russian language [Slovar' sinonimov russkogo jazyka], Russian language, Moscow, 600 p.

2. Arutyunova, N. D. (1988), Estimation. Event. Fact [Ocenka. Sobytie. Fakt], Nauka, Moscow, 341 p.

3. Bulgarian-Russian Dictionary, (1966), [Bolgarsko-russkij slovar'], Soviet Encyclopedia, Moscow, 768 p. 228 p.

4. Wolf, E. M. (1985), The functional semantics of the estimate [Funkcional'naja semantika ocenki], Nauka, Moscow,

5. Dimitrova, M., Spassova, A. (1980), A synonym dictionary of contemporary Bulgarian literary language [Sinonimen rechnik na s»vremennija b»lgarski knizhoven ezik], Publishing House of the Bulgarian Academy of Sciences, Sofia, $734 \mathrm{p}$.

6. Dineva, A. (1985), "Semantics of the Cognitive Verbs in Bulgarian Language», The Bulgarian language ["Semantika na kauzativnite glagoli v b»lgarski ezik», B»lgarski ezik], Sofia, No. 2, pp. 140-148.

БОGВА Евеліна Володимирівна,

кандидат філологічних наук, доцент кафедри української та зарубіжної літератур Державного закладу «Південноукраїнський національний педагогічний університет імені К. Д. Ушинського»,

вул. Старопортофранківська, 26, Одеса, 65020, Україна; тел.: +38 048 7234098; e-mail: evelinaboeva@gmail.com; ORCID ID: 0000-0001-5966-0538

\section{СЕМАНТИЧНА ПОЛЯРИЗАЦІЯ ІМЕН, ЩО ЛІКВІДУЮТЬ ДІЇ В РОСІЙСЬКІЙ І БОЛГАРСЬКІЙ МОВАХ}

Анотація. Актуальністьроботи визначається як наростаючим інтересом до зіставно-типологічного вивчення мов, так і спробами узагальнити накопичені спостереження над специфікою мовного вираження на різних рівнях, пошуком адекватних моделей співвідношення мовного і позамовного. Предметом вивчення є російські та болгарські дієслова і лексикографічні інтерпретації їхніх значень. Матеріалом дослідження послужили тлумачні, синонімічні та перекладні словники російської та болгарської мов. Основною метою дослідження є визначення семіотичних підстав імпліцитності, типізація цих підстав і створення адекватної моделі співвідношення мовного й позамовного як для однієї мови, так і для двох мов, що знаходяться у відношенні близької спорідненості. У групі епілогових номінацій спостерігається внутрішній розподіл імен залежно від концептуальних граней результату. У групі проспективних номінацій єдність зберігається завдяки тезаурусній імплікації значень. У ці імплікації входить обов'язкове посилання на типову ситуацію, типові об'єкти і засоби ліквідації.

Ключові слова: семантична поляризація, дієслово, ліквідуюча дія, суб'єкт, об’єкт, есенціальні якості.

Evelina V. BOYEVA,

Candidate of Philology Sciences, Associate Professor of the Department of Ukrainian and Foreign

Literature of the South Ukrainian K. D. Ushynsky National Pedagogical University, 26, Staroportofrankovskaya st., Odessa, 65020, Ukraine; tel.: +38048 7234098; e-mail: evelinaboeva@gmail.com;

ORCID ID: 0000-0001-5966-0538

\section{NOUNS OF ELIMINATING ACTIONS SEMANTIC POLARIZATION IN THE RUSSIAN AND BULGARIAN LANGUAGES}

Summary. The relevance of the research is determined by an increasing interest to the comparative-typological study of languages, as well as the attempts to generalize the accumulated observations on the specifics of language expressions at different levels, search for adequate models of the relation between linguistic and non-linguistic. The subject of this study is Russian and Bulgarian verbs and lexicographic interpretations of their meanings. The material of the study was glossaries, dictionaries of synonyms, dictionary of idioms and Russian-Bulgarian dictionaries. The main purpose of the study is to establish the semiotic foundations of implicitity, to typify these grounds and to develop an adequate model of the relation between the linguistic and the sublinguistic for both one language and two languages that are closely related. Conclusions. In the group of epilogical nominations there is an internal distribution of names depending on the conceptual 
aspects of the result. In the group of prospective nominations, unity is preserved due to the thesaurus implications of meanings. These implications include a compulsory reference to the typical situation, typical objects and means of elimination.

Key words: semantic polarization, verb, eliminating action, subject, object, essential qualities.

Статтю отримано 19.04.2018 p.

http://dx.doi.org/10.18524/2307-4558.2018.29.139328

уДК 811.111’373.2:528.5-523.8:793.7

ВАРБАНЕЦЬ Тетяна Вікторівна,

викладач кафедри іноземних мов Національного університету “Одеська юридична академія»; вул. Академічна, 2, м. Одеса, 65009, Україна; тел.:+38 066 7362484; e-mail: proffessor.tatyana@icloud.com; ORCID ID: 0000-0002-4278-0442

\section{ОНІМНА СПЕЦИФІКА НАЗВ КВЕСТІВ В ЕЛЕКТРОННИХ ІГРАХ}

Анотація. Об'єктом дослідження є оніми на позначення об'єктів віртуальних світів електронних ігор (віртуалміфооніми) в англійській мові. Предметом дослідження є функціональні, мотиваційні, словотвірні й структурні особливості одного з класів віртуалміфонімів - віртуалміфоквестонімів. Матеріалом дослідження слугує картотека з 200 віртуалміфоквестонімів зі гри The Witcher 3: Wild Hunt. Висновками роботи можна вважати такі положення: 1) головні функції віртуалміфоквестонімів - систематизувати й розбивати на етапи ігровий досвід, а також полегшувати орієнтацію в ігровому світі; 2) цими цілями зумовлено їх структурну та дериваційну специфіку: найрозповсюдженішими є складені віртуалміфоквестоніми, утворені за допомогою словоскладання, які дозволяють якомога повніше описати сутність квесту; 3) щодо мотивації віртуалміфонімів, найчастіше функціонує пропозиційна мотивація, що покликано полегшити орієнтацію гравця у віртуальному всесвіті.

Ключові слова: електронна гра, віртуалміфонім, віртуалміфоквестонім, квест.

Постановка проблеми. Сучасні технології пронизують всі сфери життя людства, в тому числі й розваги. 3 кожним роком все популярнішими стають електронні ігри на різних платформах: комп'ютери, мобільні телефони, ігрові консолі тощо. Електронні ігри є актуальним об'єктом дослідження для різних наук, зокрема їхній лінгвістичний складник - для мовознавства.

Майже кожна електронна гра має власний лор - вигаданий світ, у якому трапляються сюжетні події гри, зі своєю специфікою, персонажами, історією тощо. Його невід'ємним та одним із центральних складників є ономастикон, тобто сукупність усіх власних імен [1], за допомогою якого підтримується єдність і цілісність цього вигаданого світу, особливо за умови існування декількох ігор у цьому всесвіті чи фольмів або книжок, які розвивають та поглиблюють його події. Саме оніми на позначення об'єктів віртуальних світів електронних ігор (віртуалміфоніми) в англійській мові $\mathrm{G}$ об'єктом vernacular нашого дослідження.

Постановка дослідницьких завдань. У попередніх розвідках будо окреслено різні лінгвальні особливості віртуалміфонімів [див. докладніше: $2 ; 3 ; 4]$. У цій статті предметом дослідження 6 функціональні, мотиваційні, словотвірні й структурні особливості одного з класу віртуалміфонімів віртуалміфоквестонімів, які дефінуємо як (власні назви завдань у комп'ютерній грі, назви місії чи рівня) [5, с. 57]. Матеріалом дослідження слугує 200 картотека з віртуалміфоквестонімів з гри TheWitcher 3: WildHunt.

Виклад основного матеріалу. Клас віртуалміфоквестонімів є винаходом розробників електронних ігор, який спрямовано на систематизацію досвіду гравця через розбивання цього досвіду на певні етапи. Вони називають квести - завдання, які головний герой електронної гри отримує від іншого персонажа, після виконання яких він зазвичай одержує нагороду [8]. Цей клас онімів можна розділити на два великих підкласи [див. докладно: 5, с. 57]:

- Назви основних квестів, які називають події, що формують лінію сюжету в електронній грі. Їх виконання є обов'язковим для просування у грі й, фактично, є тим, заради чого гравець грає в гру. Як зазначає М. Карпенко, ці назви є більш креативними: вони часто містять метафори, метонімії, алюзії, фрагменти фразеологізмів. На нашу думку, для цього є два приводи: 1) розробники не бажають назвою розкривати несподівані напрямки розвитку сюжету; 2) події цих квестів часто є надто складними для буквального опису однією фразою. Прикладом цього підкласу віртуалміфоквестонімів може виступати квест Family Matters з аналізованої гри, в якому потрібно розплутати сімейну драму центральних персонажів. Назва вірогідно є алюзією на американський серіал з такою самою назвою;

- Назви другорядних квестів, які є більш описовими. Це може бути пов'язано з тим, що вони не відображають якісь значущі сюжетні події, а зазвичай слугують для того, щоб вказати / нагада- 